\title{
Epidemiology of Time-Loss Injuries in Senior and Under-18 Portuguese Male Rugby Players
}

\author{
by \\ Antonio Miguel Cruz-Ferreira1,2,3, Eduardo Miguel Cruz-Ferreira ${ }^{1,3,4}$, \\ Pedro Barbosa Ribeiro ${ }^{3}$, Luiz Miguel Santiago ${ }^{5,6}$, Luis Taborda-Barata ${ }^{1,7}$
}

\begin{abstract}
Rugby union has one of the highest injury incidence rates in team sports, however, most of the available data focus on the epidemiology of injuries in countries where rugby is popular. We aimed to report the incidence rate and relevant epidemiological aspects of injuries occurred in a group of Portuguese male rugby players. A prospective cohort study was conducted with a group of 45 senior and 32 under-18 male players (total of 77 players). Outcome measures included injury incidence, position, type, location and severity of injuries. The match injury incidence for all players was 55.84 per 1000 player match-hours (66.66 for seniors, 42.85 for under-18), while mean time-loss for injury was 20.79 days. No statistical differences were found between groups. Lower limb injuries accounted for $60.5 \%$ of all injuries, while joint/ligament injuries were the most prevalent type. Contact events were responsible for $65.1 \%$ of injuries. Despite the limitations, the obtained data are consistent with the literature. Time-loss injuries seem highly prevalent in rugby union and the incidence rates found in this Portuguese-based study were lower than the reported for international and senior men's professional rugby union, but higher than those occurring in community rugby in tier-1 countries. The authors believe these data reinforce the need to develop and implement effective injury surveillance and prevention programs.
\end{abstract}

Key words: athletic injuries; injury surveillance; rugby union.

\section{Introduction}

Rugby is a fast growing sport, gaining significant relevance and interest from the general public and the scientific community, especially after the introduction of professionalism, 20 years ago (Freitag et al., 2015). A major aspect that draws the attention of researchers is the incidence of injuries, associated with the nature of the sport, which involves significant, intense and repeated contact with the opponent (Bathgate et al., 2002; Fuller et al., 2008, 2013; Williams et al., 2013; Lehnert et al. 2018). Rugby specific characteristics include players intense physical confrontation and high-speed running, resulting in a significant risk of injury with several studies reporting injury incidences of up to 89.1 per 1000 player matchhours in international and professional rugby fifteens levels (Fuller et al., 2013; Williams et al., 2013; Stastny et al., 2016), whereas at junior level, the injury incidence ranged from 34 to 45 per 1000 player match-hours, in relevant studies published (Haseler et al., 2010; Palmer-Green et al., 2013). At lower competitive levels in senior rugby

\footnotetext{
1 - Faculdade de Ciências da Saúde da Universidade da Beira Interior, Covilhã (Portugal).

2 - UCSP da Mealhada, Mealhada (Portugal).

3 - Associação Académica de Coimbra Rugby, Coimbra (Portugal).

4 - Serviço de Ortopedia, Hospital Sousa Martins, ULS da Guarda, Guarda (Portugal).

5 - Faculdade de Medicina da Universidade de Coimbra, Coimbra (Portugal).

6 - USF Topázio, Coimbra (Portugal).

7 - Serviço de Imunoalergologia do Centro Hospitalar da Cova da Beira, Covilhã (Portugal).
} 
(community and amateur), however, injury incidence rates are lower and studies published until now, particularly in countries where rugby is more popular, report rates of 21.7 per 1000 player match-hours (Roberts et al., 2013), which are even lower than those reported for youth levels. The higher incidence of injuries reported in some studies conducted in youth rugby, when compared to amateur senior players, has not yet been fully explained. However, it can be associated to high levels of intensity in athletes with a mismatch in terms of physical attributes, as well as poor tackle and contact techniques (Palmer-Green et al., 2013).

Most data suggest that in rugby union, muscle/tendon and joint/ligament injuries of the lower limb are most prevalent, and that there are no significant differences between players from different positions in terms of injury incidence rates (Fuller et al., 2013; Palmer-Green et al., 2013; Roberts et al., 2013; Williams et al., 2013). On average, injuries in rugby union fifteen players result in an absence of 20 days (Fuller et al., 2013; Palmer-Green et al., 2013; Roberts et al., 2013; Williams et al., 2013).

In Portugal, senior male competitions are divided into three competitive levels: the lowest and the intermediate levels are almost exclusively amateurs; the highest competitive level (Divisao de Honra) has several professional and semiprofessional players, thus enhancing the competitive standards of the league (CruzFerreira and Ribeiro, 2013a, 2013b). At youth levels, competition formats vary quite significantly, but teams usually compete in a national tournament played throughout the season on natural and artificial grass fields.

As seen before, injury report studies in rugby are very common in countries where rugby is a popular sport as England, Australia, New Zealand or South Africa. However, little is known regarding the epidemiology of time-loss injuries in countries struggling to grow in the world of rugby, as Portugal.

Considering the growing interest in this sport and the increasing number of players engaging in regular competition, the authors considered it relevant to promote the awareness regarding sport injuries in Portuguese rugby, as well as in all second and third tier countries, by collecting and reporting relevant data regarding match injuries in a group of senior and under 18 athletes, aiming to launch the basis for future larger and more relevant studies in this field.

We aimed to report the incidence rate and relevant epidemiological aspects of injuries, such as association to contact and non-contact events, player's position, type, location and severity of injury, for each group.

\section{Methods}

\section{Participants}

All senior male players $(n=45)$ from a top division Portuguese rugby club (age: $21.40 \pm 3.55$ years; body height: $1.79 \pm 0.06 \mathrm{~m}$; body mass: $87.06 \pm 12.54 \mathrm{~kg}$ ), and all under-18 male players (n $=32$ ) from an under-18 top division Portuguese rugby club (age: $16.04 \pm 0.58$ years; body height: $1.77 \pm 0.05 \mathrm{~m}$; body mass: $75.10 \pm 13.15 \mathrm{~kg}$ ), were included in this study.

Senior players engaged in a total of 21 official matches, each lasting $80 \mathrm{~min}$, and an average of 15 athletes played every minute of each match. Under-18s competed in a total of 20 official matches, each lasting $70 \mathrm{~min}$, and an average of 15 athletes played every minute of each match. Total match exposure time of players in hours for a team was given by $\mathrm{Nm}^{*} \mathrm{Pm} * \mathrm{Dm} / 60$, where $\mathrm{Nm}$ is the number of matches played, $\mathrm{Pm}$ is the number of players in the team (fifteen) and Dm is the duration of the match in minutes (Fuller et al., 2008). Therefore, senior players were exposed to a total of 420 player match-hours and under- 18 s to 350 player match-hours.

The study conformed to the standards set by the Declaration of Helsinki, and all players were informed about the procedures, potential risks and benefits of the research.

\section{Measures}

As considered in the consensus statement on injury definitions and data collection procedures for studies of injuries in rugby union (Fuller et al., 2007, 2008), information was recorded on the date of the injury, the return to play date, characteristics of the time-loss injury (new versus recurrent, type and its location and event) and the player's position (Fuller et al., 2007, 2008). Injury severity was defined by the number of days missed by the player and grouped as: minimal ( $2-3$ days), mild (4-7 days), moderate (828 days) and severe ( $>28$ days). Recurrent injury was defined as an injury of the same type and at 
the same location as an index injury and which occurred after a player's return to full participation from the index injury. Injuries were classified, according to the consensus statement on injury definitions and data collection procedures for studies of injuries in rugby union by location, type and injury event (Fuller et al., $2007,2008)$. Absences from training or match play due to other causes (illness or injuries occurring in other activities) were not considered by the research team, since only match injuries were reported. Playing positions were grouped as forwards (props, hooker, second row and back row) and backs (scrum and fly halves, centres, wingers and full backs).

\section{Design and Procedures}

We conducted a prospective cohort study, between August 2014 and May 2015. The methodology used in our study was compliant with the consensus statement on injury definitions and data collection procedures for studies of injuries in rugby union (Fuller et al., 2007, 2008). To gather the significant data, the authors relied on the collaboration of the team's medical staff, who reported all injuries occurring in matches during the 2014/15 season.

\section{Statistical analysis}

The incidence of injury is reported as injuries per 1000 player match-hours; severities as mean days; proportions as percentages. For continuous variables, normality was assessed using Shapiro Wilk or Kolmogorov-Smirnov tests, when appropriate. As continuous variables were not normally distributed, Mann-Whitney and Kruskal Walis tests were used to compare the severity of injuries between groups, type and site of injury, when appropriate. The level of significance was set at $p<0.05$. All data was recorded, and descriptive and inferential analysis was performed using SPSS $® v 20.0$.

\section{Results}

A total of 43 injuries were reported, 28 occurring in senior players and 15 in the under$18 \mathrm{~s}$, corresponding to an overall incidence rate of 55.84 injuries per 1000 player match-hours. Assessing each group separately, the incidence rate was of 66.66 injuries per 1000 player matchhours for senior players and 42.86 injuries per 1000 player match-hours for the under-18s. No significant differences were found between each age group $(p=0.102)$ or between the four age/position groups $(p=0.392)$. Details are presented in Table 1.

Forwards sustained more injuries than backs in the senior group (71.42 per 1000 player match-hours, with a total of 16 injuries, compared to 61.22 per 1000 player match-hours, with a total of 12 injuries, for backs), while no differences were found between backs and forwards in the under-18 group: 42.86 per 1000 player matchhours, for both backs and forwards, respectively, with a total of 7 and 8 injuries. When comparing the total number of injuries that occurred in each age group, no statistical differences were found $(p$ $=0.193)$, nor when forwards and backs incidence rates were compared $(p=0.647)$.

Regarding the severity of injuries, no fatal or catastrophic injuries were reported. For senior players, most of the injuries were mild $(50 \%)$ or moderate $(32 \%)$. However, $18 \%$ of injuries were severe, with athletes missing training sessions or matches for 28 or more days. For the under 18 group of players, only one injury caused more than 28 days of absence, and most were classified as mild $(46 \%)$ or moderate $(46 \%)$. No statistical differences were found between the four groups previously considered $(p=0.087)$, nor between backs and forwards $(p=0.174)$ or between seniors and under-18s $(p=0.343)$.

The mean number of days missed per injury for all players was 20.79 days. The higher average injury severity was reported for the senior backs (31.83 days), followed by the under18 forwards (20.63 days), senior forwards (15.56 days) and under-18 backs (14.00 days), as presented in Figure 1. No statistical differences were found concerning the severity of injuries between the four groups $(p=0.269)$, nor between backs and forwards $(p=0.171)$ or between seniors and under-18s $(p=0.781)$.

Regarding the injury site (Figure 2), they were more frequent in lower limbs $(60.50 \%)$, followed by the trunk and upper limb (both with $14 \%)$ and the head $(11.60 \%)$. When considering the injury site, lower limb injuries resulted in a higher mean number of days missed (24.27 days per injury), compared to trunk (19.33 days per injuries), head (18.20 days per injuries) or upper limb injuries (9.33 days per injuries). No statistical differences were found between the injury site and days missed $(p=0.201)$ or injury severity 
grade $(p=0.315)$.

The most common injury types reported were joint/ligament injury (44.20\%), haematoma/contusion/bruise $(18.60 \%)$, muscle rupture/strain/tears/cramps $(14 \%)$, concussion $(9.30 \%)$, fracture and dislocation (each $7 \%$ ).

The single most severe injury recorded was a knee ligament injury (120 days missed), however, fractures were responsible for the highest mean severity (29.33 days), followed by joint/ligament injury (25.63 days), and concussion (17.50 days). See Table 2 and Figure 3 for graphical analysis of time lost by injury type. No statistical differences were found between the injury type and days missed ( $p=0.495)$ or injury severity grade $(p=0.579)$.

As expected, most injuries occurred with contact $(65.10 \%)$, but no statistical differences were found between contact and non-contact injuries in terms of days missed $(p=0.176)$ or injury severity grade $(p=0.143)$.

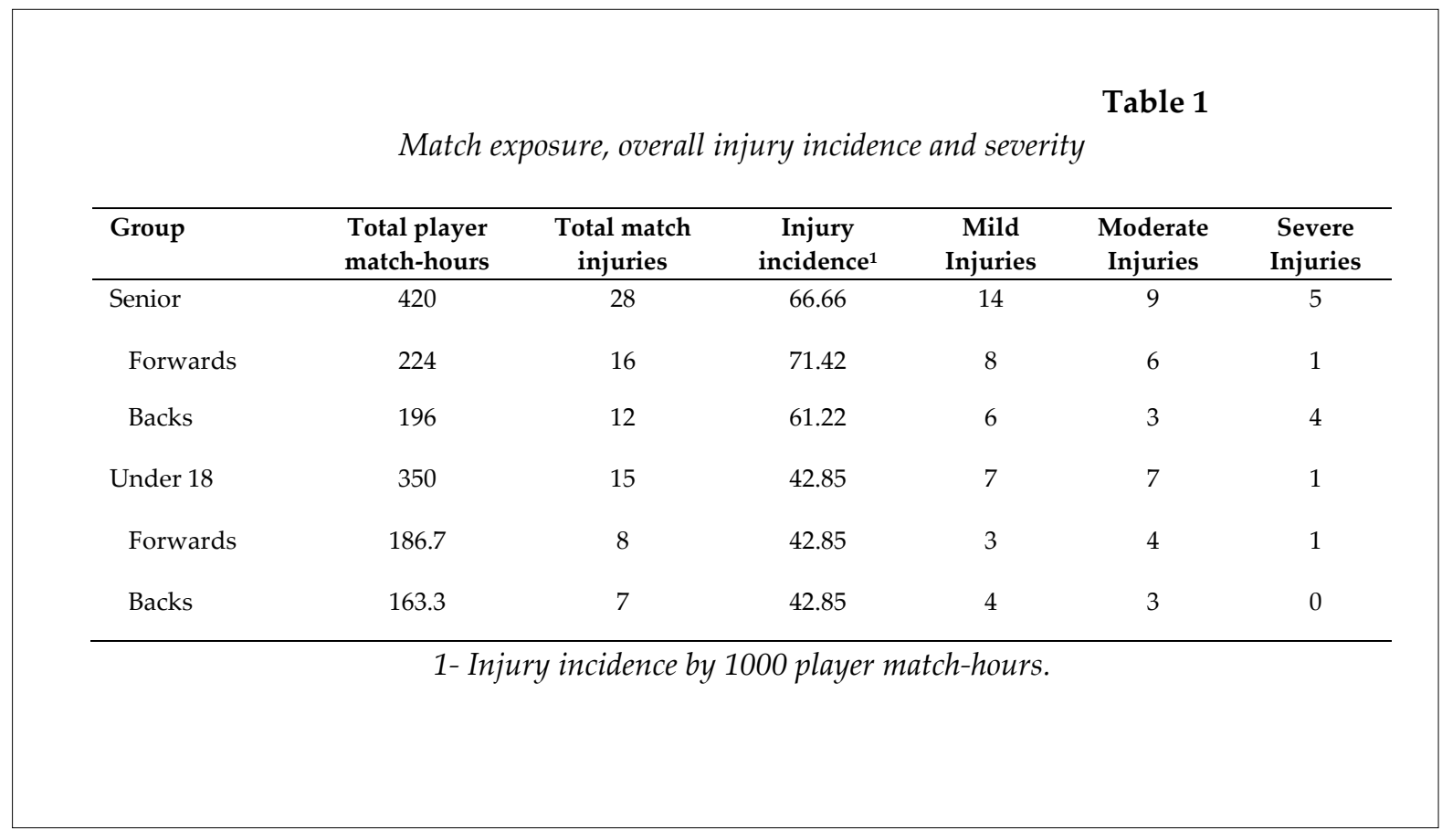

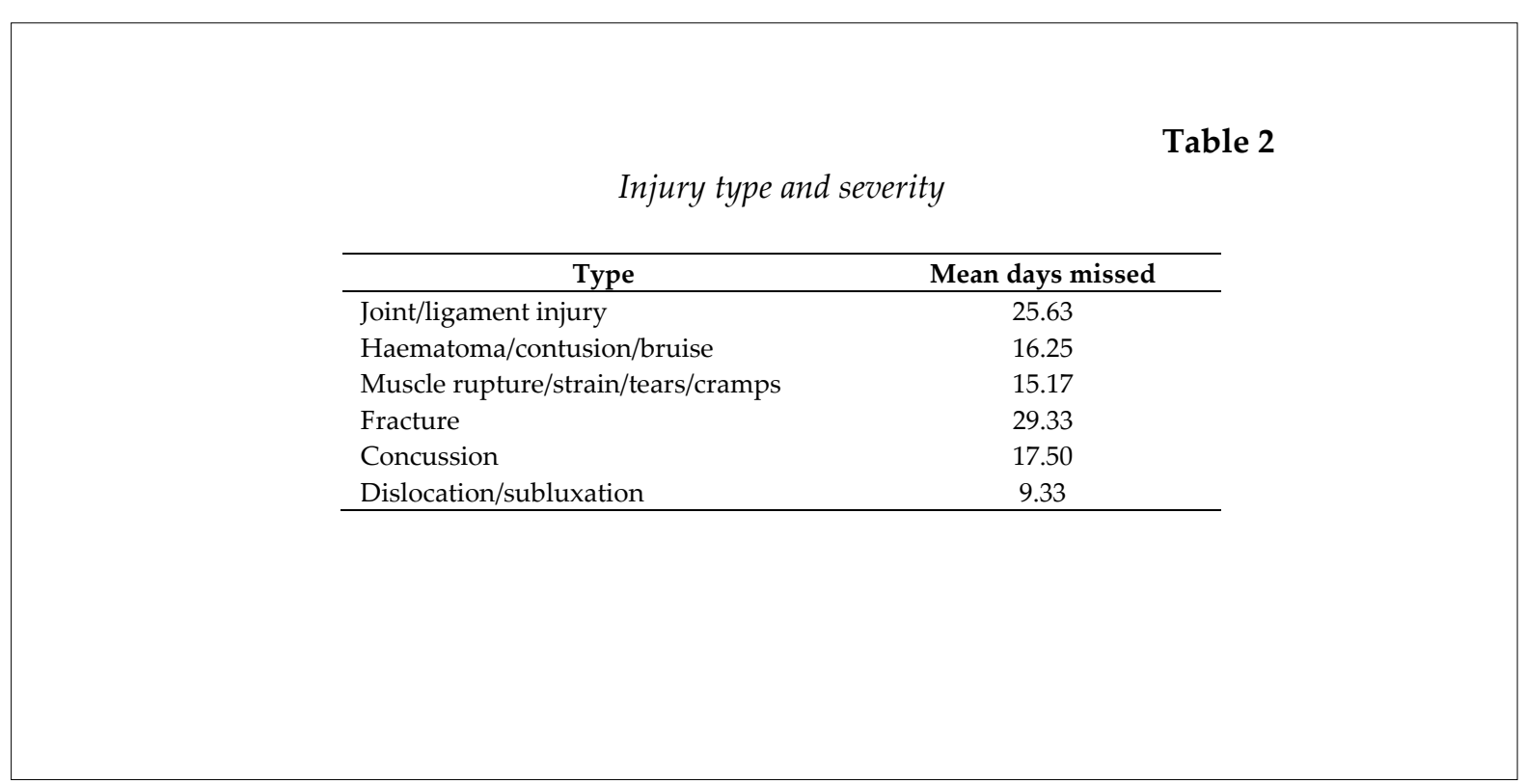




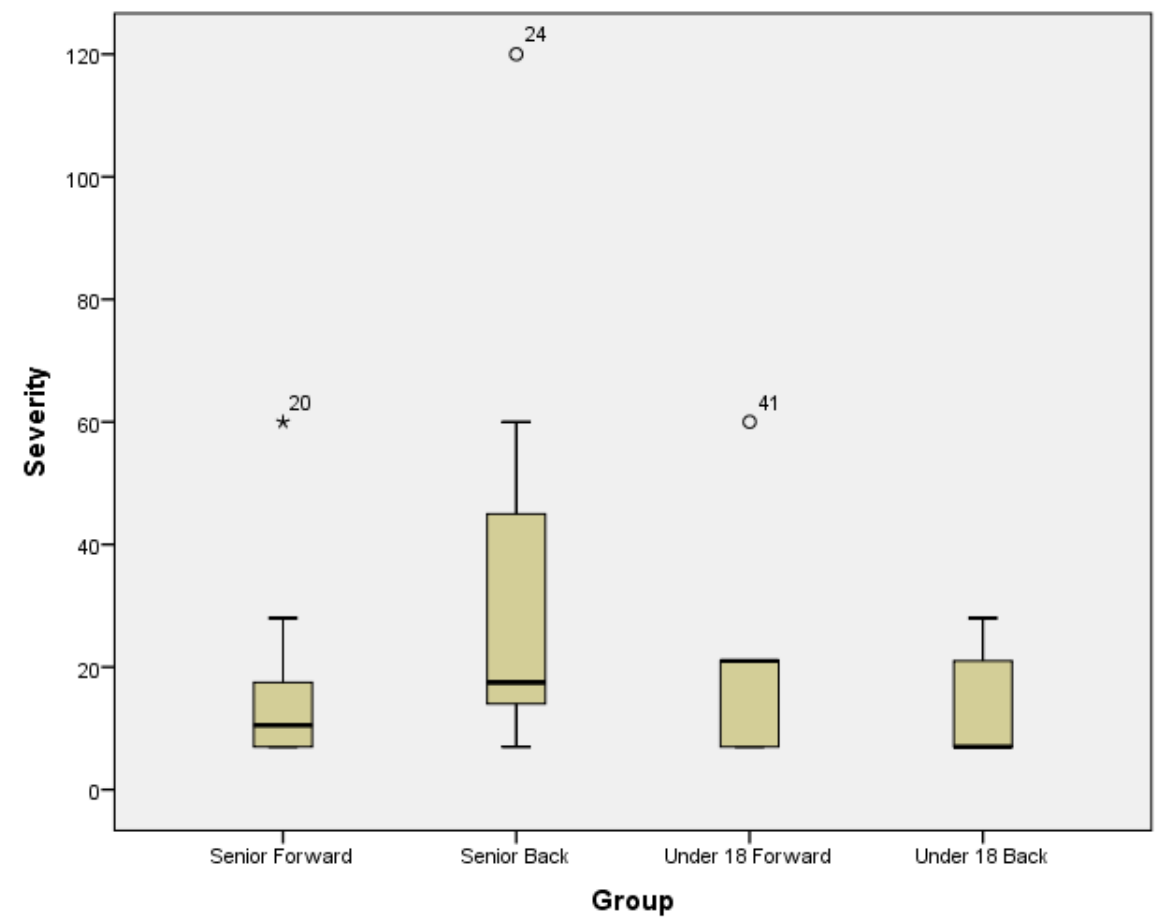

Figure 1

Severity of injuries (days missed) by positional and age group

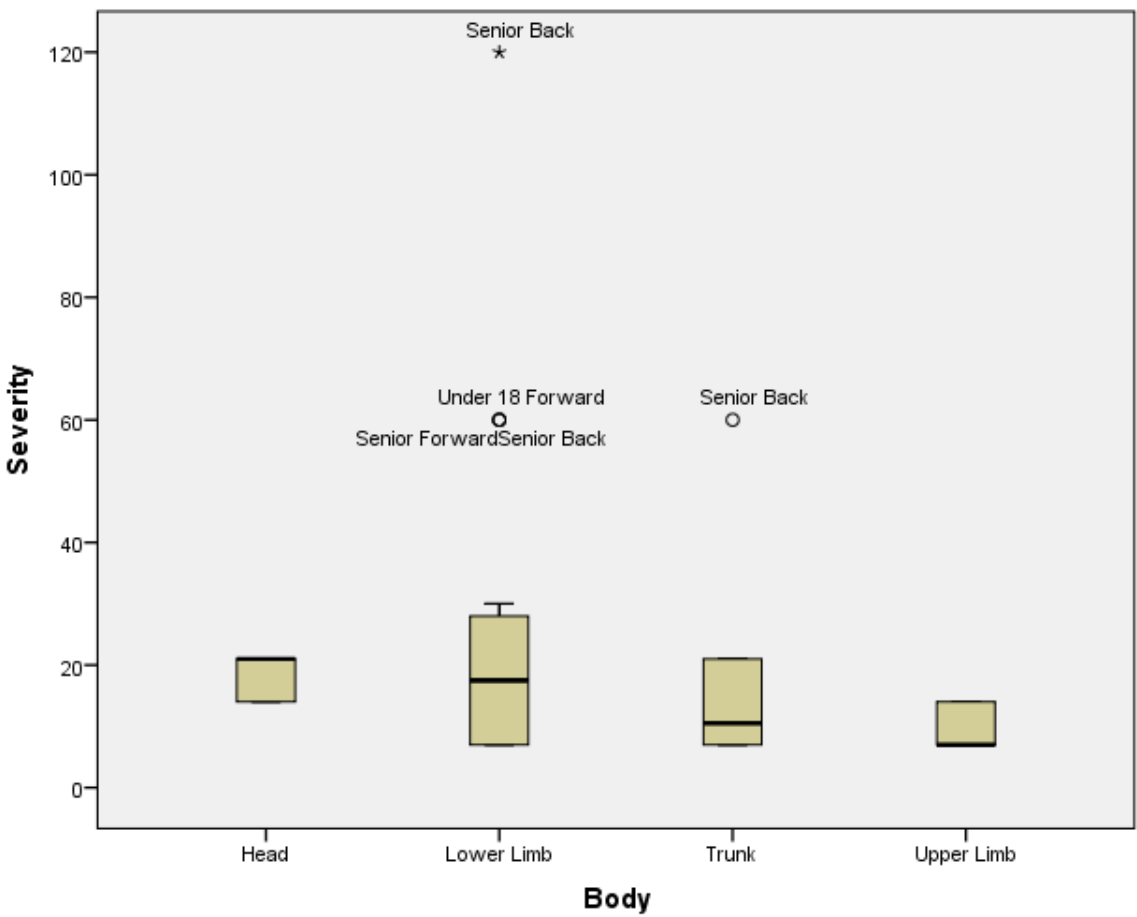

Figure 2

Severity of injuries (days missed) by injury site 


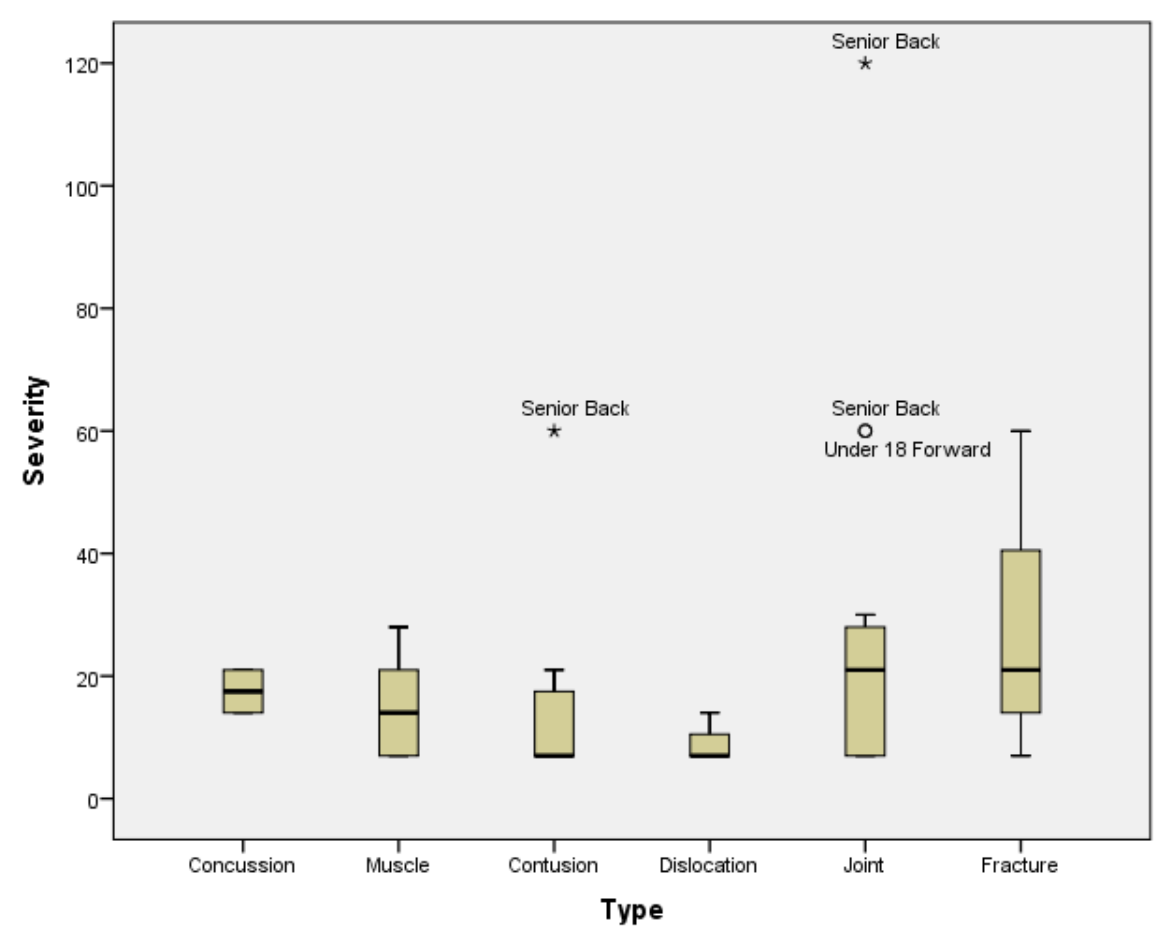

Figure 3

Severity of injuries (days missed) by injury type

\section{Discussion}

With this paper we aimed to report the incidence rate and relevant epidemiological aspects of injuries in senior and under-18 Portuguese rugby union players. As far as we know, this is one of the first studies of time-loss injuries in Portuguese rugby union ever published.

We demonstrated that the injury incidence rate in this group of Portuguese rugby players was high and contact events were associated with two thirds of injuries. Our overall injury incidence in the group of senior players (66.66 injuries per 1000 player match-hours) was, as expected, lower than that reported for professional rugby (89.1 per 1000 player matchhours) (Fuller et al., 2013; Williams et al., 2013). However, in the under-18 group, the injury incidence was in line with the available literature for that age group (Haseler et al., 2010; PalmerGreen et al., 2013).

Nevertheless, the incidence that we report for the senior group is higher than that of studies in community or semi-professional-level rugby in New Zealand (25 per 1000 player match-hours) (Schneiders et al., 2009) or England (21.7 per 1000 player match-hours) (Roberts et al., 2013).

According to literature, it is possible to link higher injury incidence to higher levels of competition, greater match play intensity and different match play demands that comprise more contact events per match (Williams et al., 2013). Although there are many limitations in our study, we believe that we showed that Portuguese rugby clubs are attempting to raise their level of competitiveness, which naturally leads to more 
intensity and greater physical demands during match play. The injury incidence rate found for the under-18 group, being approximately the same reported for British youth levels, also suggests the relatively higher level of Portuguese teams in the international rugby scene, as the recent $6^{\text {th }}$ place in the Under-18 Elite Rugby Europe Championship and the second place in the Under-20 World Rugby Trophy in 2017 may reflect, with Portugal finishing above countries with more tradition in this sport (Rugby Europe, 2015).

The most common site of injuries was the lower limb, which is in accordance with data from the available literature (Fuller et al., 2013; PalmerGreen et al., 2013; Roberts et al., 2013; Williams et al., 2013).

Another finding from our study supported by the literature is the absence of significant differences in injuries sustained by forwards and backs (Williams et al., 2013), which are minimal in the senior level and non-existent in the under- 18 .

Regarding the type of injury, joint/ligament injuries were the most common followed by contusions, with most of injuries associated to contact events. These findings are also in accordance with the literature and seem to stress the fact that high-speed running, tackle, collisions and energy transfers in open phases of the game might justify the relevant incidence of injuries found in amateur rugby players (Roberts et al., 2013).

The greater incidence of joint injuries should make rugby agents aware of the need of proper implementation of strategies to reduce these injuries. It may be beneficial to implement appropriate training routines and warm-up exercises, as well as the use of adequate protection when previous injuries are reported, although this is still a grey area (Freitag et al., 2015; Murray et al., 2014).

A large meta-analysis published in 2013, compiling information from 15 papers addressing injuries in senior men's professional rugby union (Williams et al., 2013), suggested that the mean severity for match injuries was of 20 days, which is precisely the same reported in our study.

Overall, no relevant differences were found between our study and other major studies conducted in countries with greater rugby tradition, and most of our findings were consistent with the literature. In our opinion, this study serves its purpose and should become the basis for future larger and superior quality studies to implement, with the help of all rugby agents, at top-club and elite national levels in Portugal.

Despite the obvious limitations (small sample, all athletes belonging to the same team and covering only one season), the methodology adopted, meeting the consensus statement on injury definitions and data collection procedures for studies of injuries in rugby union, ensures the quality of the conclusions that we can draw from our study.

This is, certainly, an important milestone to Portuguese rugby, especially as it helps to raise the awareness towards the need to implement effective injury surveillance and injury prevention programs in the near future.

\section{Acknowledgements}

To the board, coaches and medical staff of Associação Académica de Coimbra Rugby.

\section{References}

Bathgate A, Best JP, Craig G, Jamieson M. A prospective study of injuries to elite Australian rugby union players. Br J Sport Med, 2002; 36(4): 265-269. doi:10.1136/bjsm.36.4.265

Cruz-Ferreira AM, Ribeiro CAF. Anthropometric and physiological profile of portuguese rugby players Part I: Comparison between athletes of different position groups. Rev Bras Med do Esporte, 2013; 19(1): 48-51. doi:10.1590/S1517-86922013000100011

Cruz-Ferreira AM, Ribeiro CAF. Anthropometric and physiological profile of portuguese rugby players Part II: Comparison between athletes with different competitive levels. Rev Bras Med do Esporte, 2013; 19(1): 52-55. doi:10.1590/S1517-86922013000100011

Freitag A, Kirkwood G, Pollock A. Rugby injury surveillance and prevention programmes: are they effective? BMJ, 2015; 350: h1587-3 
Fuller CW, Laborde F, Leather RJ, Molloy MG. International Rugby Board Rugby World Cup 2007 injury surveillance study. Br J Sport Med, 2008; 42(6): 452-459 doi:10.1136/bjsm.2008.047035

Fuller CW, Molloy MG, Bagate C, Bahr R, Brooks JHM, Donson H, Kemp SPT, McCrory P, McIntosh AS, Meeuwisse WH, Quarrie KL, Raftery M, Wiley P. Consensus statement on injury definitions and data collection procedures for studies of injuries in rugby union. Br J Sports Med, 2007; 41(5): 328-331. doi:10.1136/bjsm.2006.033282

Fuller CW, Sheerin K, Targett S. Rugby World Cup 2011: International Rugby Board Injury Surveillance Study. Br J Sport Med, 2013; 47(18): 1184-1191. doi:10.1136/bjsports-2012-091155

Haseler CM, Carmont MR, England M. The epidemiology of injuries in English youth community rugby union. Br J Sports Med, 2010; 44(15): 1093-1099. doi:10.1136/bjsm.2010.074021

Lehnert M, De Ste Croix M, Xaverova Z, Botek M, Varekova R, Zaatar AMZ, Lastovicka O, STASTNY P. Changes in injury risk mechanisms after soccer-specific fatigue in male youth soccer players. J Hum Kinet, 2018; 62, doi: 10.1515/hukin-2017-0157

Murray AD, Murray IR, Robson J. Rugby Union: faster, higher, stronger: keeping an evolving sport safe. $\mathrm{Br} J$ Sports Med, 2014; 48(2): 73-74. doi:10.1136/bjsports-2012-091844

Palmer-Green DS, Stokes KA, Fuller CW, England M, Kemp SPT, Trewartha G. Match injuries in English youth academy and schools rugby union: an epidemiological study. Am J Sport Med, 2013; 41(4): 749755. doi:10.1177/0363546512473818

Roberts SP, Trewartha G, England M, Shaddick G, Stokes KA. Epidemiology of time-loss injuries in English community-level rugby union. BMJ Open, 2013; 3(11): 1-8. doi:10.1136/bmjopen-2013-003998

Rugby Europe. U18 - 2015 European championship. http://www.rugbyeurope.eu/competition-106.htm. Published 2015. Accessed February 2, 2016

Schneiders AG, Takemura M, Wassinger CA. A prospective epidemiological study of injuries to New Zealand premier club rugby union players. Phys Ther Sport, 2009; 10(3): 85-90. doi:10.1016/j.ptsp.2009.05.001

Stastny P, Bacakova R, Chytilova M, Tufano J, Golas A, Masczyk A. The Differences in shoulder muscle activity between injured and uninjured rugby players during player-tackling and bag-tackling. Trends Sport Scienc, 2016; 4(23): 185 - 191

Williams S, Trewartha G, Kemp S, Stokes K. A Meta-Analysis of Injuries in Senior Men's Professional Rugby Union. Sport Med, 2013; 43(10): 1043-1055. doi:10.1007/s40279-013-0078-1

\section{Corresponding author:}

\section{Antonio Miguel Cruz-Ferreira}

Faculdade de Ciências da Saúde da Universidade da Beira Interior, Covilhã (Portugal)

Rua Principal - Paredes S/N, 3020-285, Coimbra, Portugal

Phone: 00351275329002

E-mail: antonio.cruz.ferreira@ubi.pt 